\title{
Highway Construction Productivity Measurement with a Wireless Real-Time Productivity Measurement System
}

\author{
Seonghoon Kim, Yong Bai, Yang-Ki Jung, and Dukgeun Yun
}

Improving the quality of construction schedules calls for development of an advanced productivity measurement system. Existing on-site construction productivity measurement methods have some common limitations, such as not providing data necessary for engineers and project managers to conduct real-time analyses and share data with other project participants. A wireless real-time productivity measurement (WRITE) system was developed to address those shortfalls. The field experiment was conducted at two different stages: asphalt paving projects, including hot-mix asphalt and hot-in-place recycling, and a bridge reconstruction project. Productivity data collected from the WRITE system were also compared with productivity data collected from construction documents, such as contractors' daily logs and pay estimate documents, to identify the feasibility of this system for measuring the performance of construction projects. For data analyses, statistical methods such as normality test, paired $t$-test, and Wilcoxon signed-rank test were used. The result of statistical analyses proved that the developed system generated identical productivity measurements compared with the stopwatch method and construction documents. The success of this research project made several major contributions to the advancement of the construction industry. First, the research advanced the application of wireless technology in highway construction operations. Second, it provided an advanced technology for engineers and project managers to determine productivity in real time. Third, productivity data can be shared between project participants via the Internet. With these advancements, communication and coordination will be improved at construction sites. Consequently, the WRITE system will enhance owners' and contractors' ability to manage construction projects.

Currently, most of the construction schedules are developed by using the critical path method (cpm). A scheduler builds a cpm network based on the duration of construction activities and relationships between activities, with the consideration of resource

S. Kim, Department of Construction Management and Civil Engineering Technology, Georgia Southern University, 1007 Carruth Building, Statesboro, GA 30460. Y. Bai, Department of Civil, Environmental, and Architectural Engineering, University of Kansas, 1530 West 15th Street, 2135-B Learned Hall, Lawrence, KS 66045. Y.-K. Jung, Transport Safety and Welfare Division, Ministry of Land, Transport, and Maritime Affairs, Gwacheon 427-712, South Korea. D. Yun, Highway Research Division, Korea Institute of Construction Technology, Goyang-Si, Gyeonggi-Do 411-712, South Korea. Corresponding author: S. Kim, shkim@georgiasouthern.edu.

Transportation Research Record: Journal of the Transportation Research Board, No. 2228, Transportation Research Board of the National Academies, Washington,

D.C., 2011, pp. 26-33.

DOI: 10.3141/2228-04 constraints. The duration of activities is based on historical data (similar work done in the past) or an estimation done by someone in the company (e.g., project manager, project engineer, or superintendent). Construction duration is estimated by using the following formula:

duration $=\frac{\text { quantity of work }}{\text { construction productivity }}$

Because the quantity of work is relatively easy to estimate accurately by using printed drawings or computer-assisted drafting system and specifications, the accuracy of the duration depends largely on the accuracy of construction productivity. It is not difficult to understand why a scheduler without accurate productivity data is unable to produce a reliable cpm schedule. In summary, poor productivity data affect the accuracy of activity duration; inaccurate activity duration makes it impossible to produce a reliable construction schedule. To improve the quality of construction schedules, there is a need to develop an advanced productivity measurement system that will overcome mentioned shortfalls.

\section{RESEARCH OBJECTIVE AND SCOPE}

The first objective was to develop the wireless real-time productivity measurement (WRITE) system that is capable of measuring onsite construction productivity. The second objective was to determine whether the WRITE system could be used for measuring equipment and labor productivity of highway construction operations. To achieve the second objective, design field experimental procedures and field experiments, including data collection and analysis, were conducted to test the feasibility of the WRITE system as a productivity measurement tool. The third objective was to identify the possibilities of implementing the WRITE system and make recommendations for future research.

\section{RESEARCH METHODOLOGY}

The literature survey was conducted first. Construction productivity measurement methods and theories of statistics were included. The researchers designed the field experiments including the site selection, layout, procedures, data collection, and statistical data analysis methods. They also defined construction activities and operations and simultaneously collected productivity data. The developed system was tested in equipment-intensive projects [the asphalt overlay project 
and the hot-in-place recycling (HIR) project] and in a labor-intensive project (the bridge construction project).

Data collection and analyses were conducted on the basis of knowledge of the statistical experimental design process. Statistical experimental design, or design of experiment, is often used to minimize the effect of errors, reduce the number of experiment runs, and improve systems (1). Experiments involving statistical data analysis must be strategically designed to eliminate bias, avoid wasting resources, and reduce variations (2). In this research project, paired design, a comparative statistical method, was used to reduce bias and increase precision. This test begins with the null hypothesis that there is no difference between two productivity measurement methods $\left(H_{0}: \mu_{1}-\mu_{2}=\mu_{d}=0\right)$.

The researchers determined statistically whether the WRITE system can produce accurate productivity data for highway construction. The statistical analysis system (SAS) was used to analyze the collected data. The rest of the paper is organized as follows. First, the framework of the WRITE system is introduced. Second, field experiments and data collection will be outlined. Third, data analysis results will be presented. Finally, conclusions, contributions, and recommendations will be presented.

\section{LITERATURE REVIEW}

\section{Construction Productivity}

Productivity has been widely used as a performance indicator to evaluate construction operation through the entire construction phase. Construction companies have to track productivity continuously to gauge their performance capacity to maintain profitability and to prepare for future biddings (3). Because the duration of a construction activity is calculated simply by dividing the quantity of work by the productivity, productivity analysis is a major task for predicting a project schedule (4).

\section{Productivity Measurement Methods}

The purposes of measuring productivity are to identify cost-effective methods in construction operations and to obtain accurate and consistent labor productivity data (5). Productivity data are essential to estimators, labor contract negotiators, and those responsible for training the labor force and determining cost indices (6). As of today, construction labor productivity still remains the most difficult to understand in the U.S. economy because there are so many factors that could affect labor productivity (7).

Productivity data collection methods can be inconsistent because various methods of gathering data exist, resulting in difficulties interpreting and sharing the data. Traditionally, numerous types of productivity measurement techniques use the motion and time study theory. Examples of these techniques include stopwatch study, photography, videotaping, time lapse video, activity sampling (work sampling), craftsman's questionnaire survey, and a foreman delay survey $(5,8)$.

Recently, several technology advances for improving the data collection method and analyses have been studied and compared. For example, Global Positioning System and radio frequency identification technology track the progress of the resources or activities. These positioning data have been used to conduct data analyses in the case study of concrete drainable pipe installation (9). Navon and Shpatnitsky used Global Positioning System technology to measure earthmoving performance automatically by identifying the locations of equipment at regular time intervals and converting the information into a project performance index (10). The laser scanning technology was developed to recognize objects in a scene by integrating planning technologies, making it possible to visualize the $3 \mathrm{D}$ status of a project and automate tasks related to project control (11).

Existing on-site construction productivity measurement methods have some common limitations such as not providing data necessary for engineers and project managers to conduct real-time analyses and share data with other project participants. To improve the quality of construction schedules, there is a need to develop an advanced productivity measurement system that will overcome mentioned shortfalls. An ideal method of measuring construction productivity should be (a) able to monitor multiple trades in one job site, $(b)$ simple, $(c)$ inexpensive, $(d)$ consistent and replicable, $(e)$ reflective of what actually occurs at the site, and $(f)$ able to produce expeditious actions by management $(5,12)$.

\section{WIRELESS REAL-TIME PRODUCTIVITY MEASUREMENT SYSTEM}

Existing construction productivity measurement methods take longer to transmit data and pose difficulties for sharing and communicating data among participants involved in construction operations. To address these shortfalls, the WRITE system has been developed. The technology beneath the system is the integration of wireless technology and time-lapse filming (one of the time-study techniques). The WRITE system can provide pictorial data via a wireless network so that anyone in the construction field office or home office can monitor construction activities and analyze productivity in real time, as long as an Internet service is available at the location.

The WRITE system has several unique advantages. First, there is no disruption of construction operations. The WRITE system was designed to be used effectively in any field condition, such as adverse weather, and can be operated by one person. Second, the on-site construction productivity can be determined in real time so that the project manager will be able to take action immediately if necessary. Third, the collected data can be shared by all participants in the construction project via the Internet at any time and at any location. Fourth, labor and equipment cost for measuring productivity is relatively inexpensive. Fifth, the system uses videotaping as well as time-lapse video so that the system can provide an accurate interpretation of a construction operation.

\section{WRITE SYSTEM COMPONENTS}

The Erdman Video System and Verizon Wireless as an Internet service provider were used to develop the WRITE system. The WRITE system is made up of four major components, shown in Figure 1. Their functions are briefly described as follows:

1. Pan-tilt camera housing (upper right of Figure 1). This steel box contains a digital camera and a video camera, which are connected to the data processor. The video camera can take up to 30 pictures every second, and the digital camera can take high-resolution pictures (7 megapixels). The camera housing is weatherproof and vandalism resistant. It is mounted on a rugged $360^{\circ}$ outdoor pan-tilt unit, which can be attached to a pole, wall, or pedestal mount. 


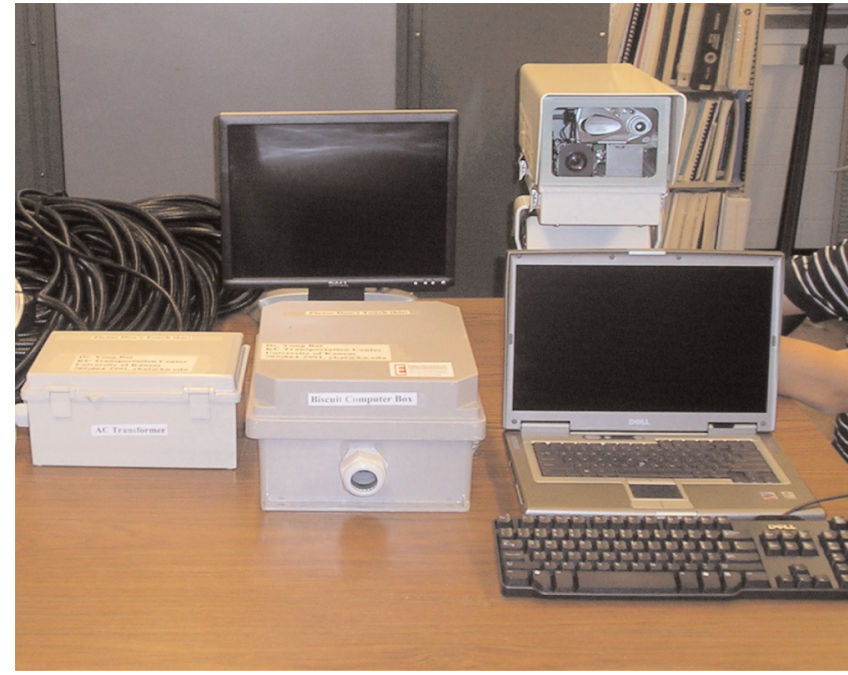

FIGURE 1 Major components of WRITE system.

2. Data processor (second item from left in first row of Figure 1). The data processor, also known as a biscuit computer or minicomputer, contains a program called VM95 that can control the camera housing movement, the number and duration of shots, and the zooming.

3. AC transformer (first item from left in first row of Figure 1). This device transfers electric energy to other circuits.

4. Laptop computer (bottom right of Figure 1). This is a necessary item for anyone who wants to view the pictorial data at a different location via a wireless modem or a local area network. If the computer is equipped with VmView software as shown in Figure 2, the computer can control the cameras with adjustments such as zoom in and zoom out.

In addition to these major components, the items that are required to operate the system include wireless modems, a generator to pro- vide electricity at the job site, a steel pole on which to mount the camera box, and cables to connect the components.

Figure 3 presents the framework of the WRITE system developed during the process of this research project. Once the video camera takes pictures from a construction site, the data processor immediately saves the pictorial data into files. These files are transmitted in real time via a wireless modem. An engineer or project manager can then access the data files via a wireless modem and the IP address at another location to conduct productivity analysis with the use of computer software.

\section{FIELD EXPERIMENT AND DATA COLLECTION}

The primary objectives of this field experiment were to $(a)$ determine whether the WRITE system is feasible for measuring construction productivity and $(b)$ identify the advantages and limitations of this system by conducting a case study. To accomplish the objective, productivity data were collected simultaneously by using the stopwatch method (Figure 4a) and the WRITE system (Figure 4b).

The stopwatch method is a classic productivity measurement method developed by Frederick W. Taylor in 1880 (13). The method uses a stopwatch to record the time spent on each human movement to complete an operation and categorizes each movement as direct work, supportive work, or nonworking $(8,14)$. The productivity is computed on the basis of the percentages of direct work, supportive work, and nonworking within a certain duration. Results from the stopwatch method and the WRITE system were compared by using statistical methods to determine whether there was a significant difference. Figure 5 shows a data collection form for this project and a sample data set that was used for statistical analysis.

The field experiment was conducted at three asphalt paving projects and one bridge reconstruction project. A hot-mix asphalt (HMA) overlay project and two hot-in-place recycling (HIR) projects were selected as equipment-intensive projects, and the bridge reconstruction project was deemed to be a labor-intensive project.

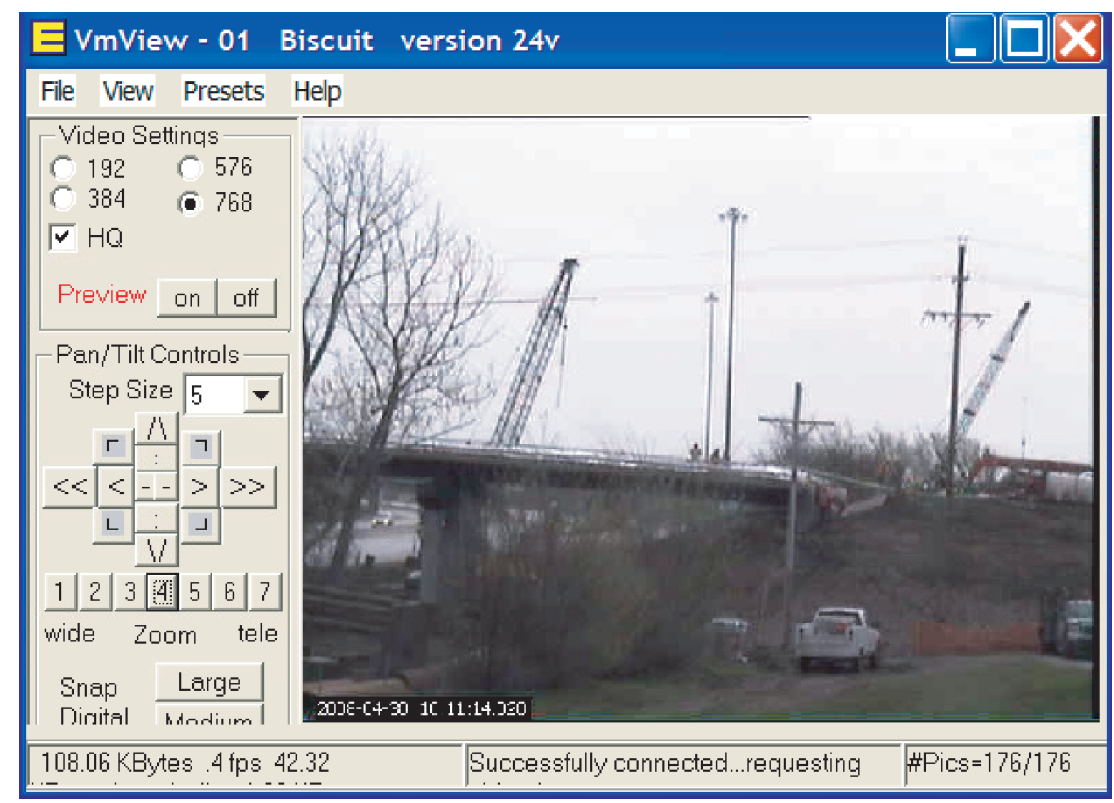

FIGURE 2 Snapshot of VmView program. 


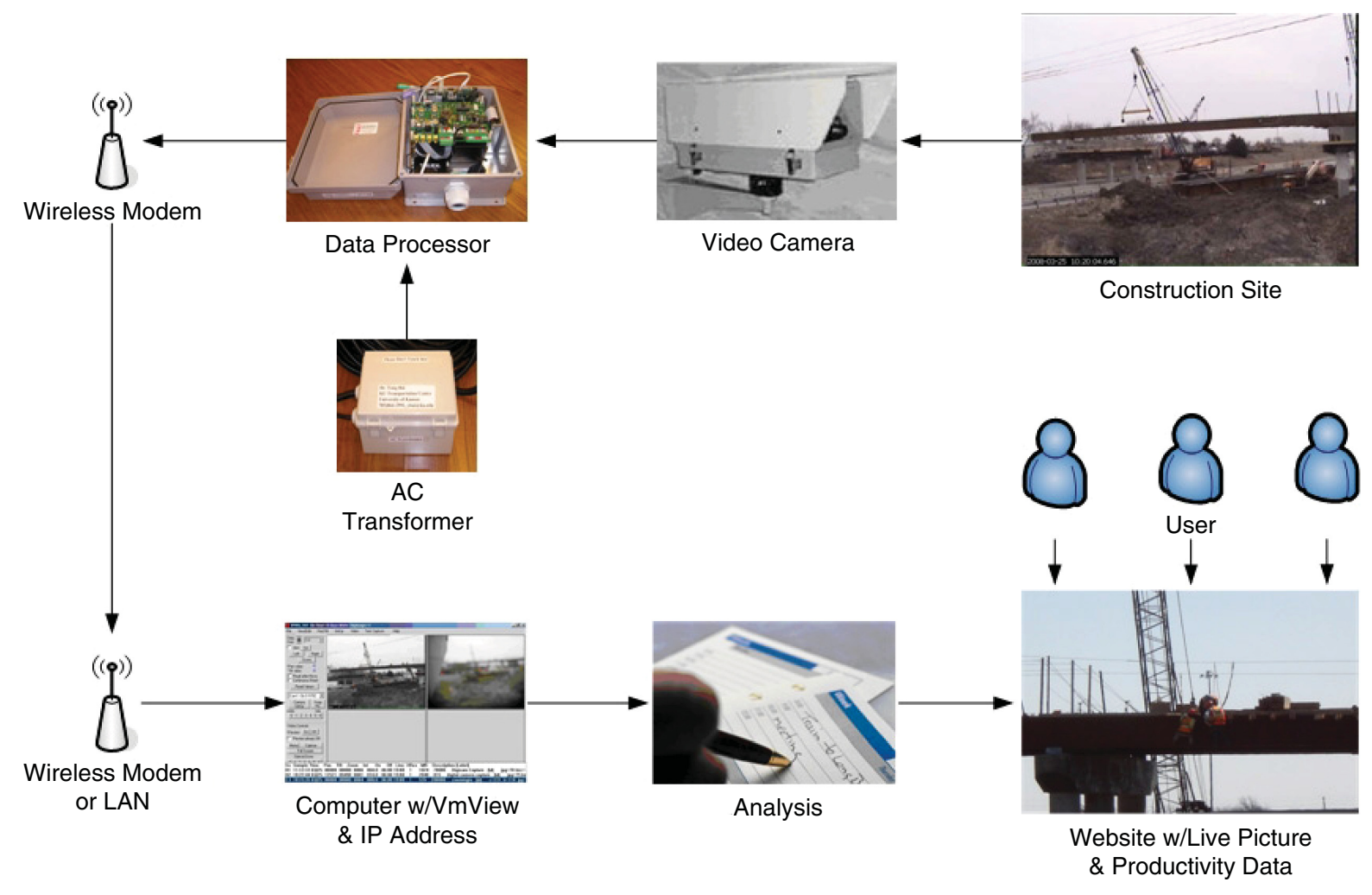

FIGURE 3 Framework of the WRITE system (LAN = local area network).

\section{HMA Overlay}

The most typical rehabilitation treatment for low-volume HMA pavement is a thin HMA overlay. The HMA overlay project was carried out by paving a net length of $9.176 \mathrm{mi}$ with a thickness of $1.5 \mathrm{in}$. and a width of $31 \mathrm{ft}$ on US-36 near Washington, Kansas. Hall Brothers, Inc., the contractor, was awarded the project at $\$ 983,798$, including milling, bituminous overlay, and shoulder rock (Figure 6). The estimated duration was 12 working days from June 11 to June 25,

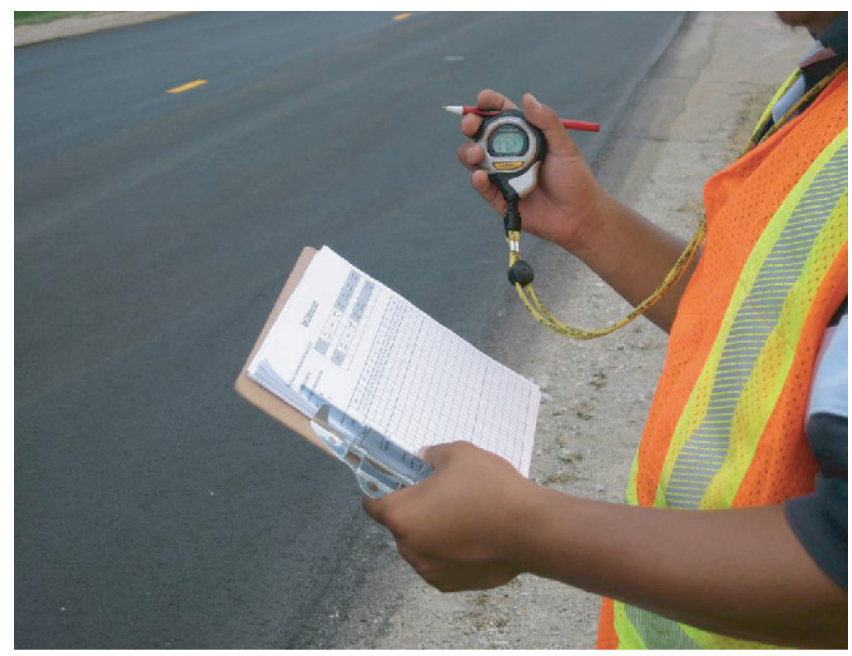

(a)
2007. Productivity data were collected on the operation for 4 days from June 18 to June 21, 2007.

\section{HIR Operation}

HIR is an asphalt recycling method, used in the United States since the 1980s, that removes pavement surface materials by using heat and then combines them with new pavement materials and

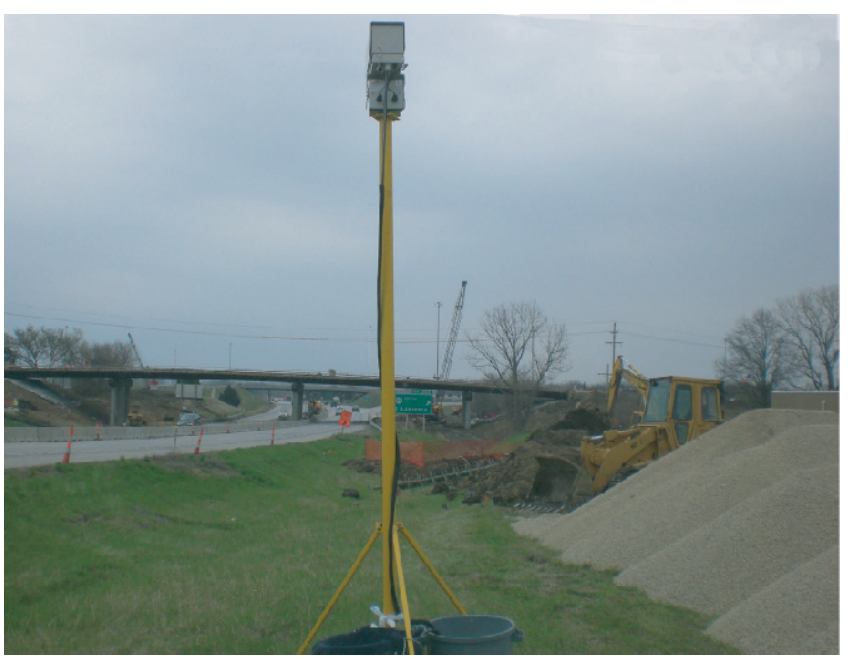

(b)

FIGURE 4 Time study using (a) a stopwatch and $(b)$ the WRITE system. 


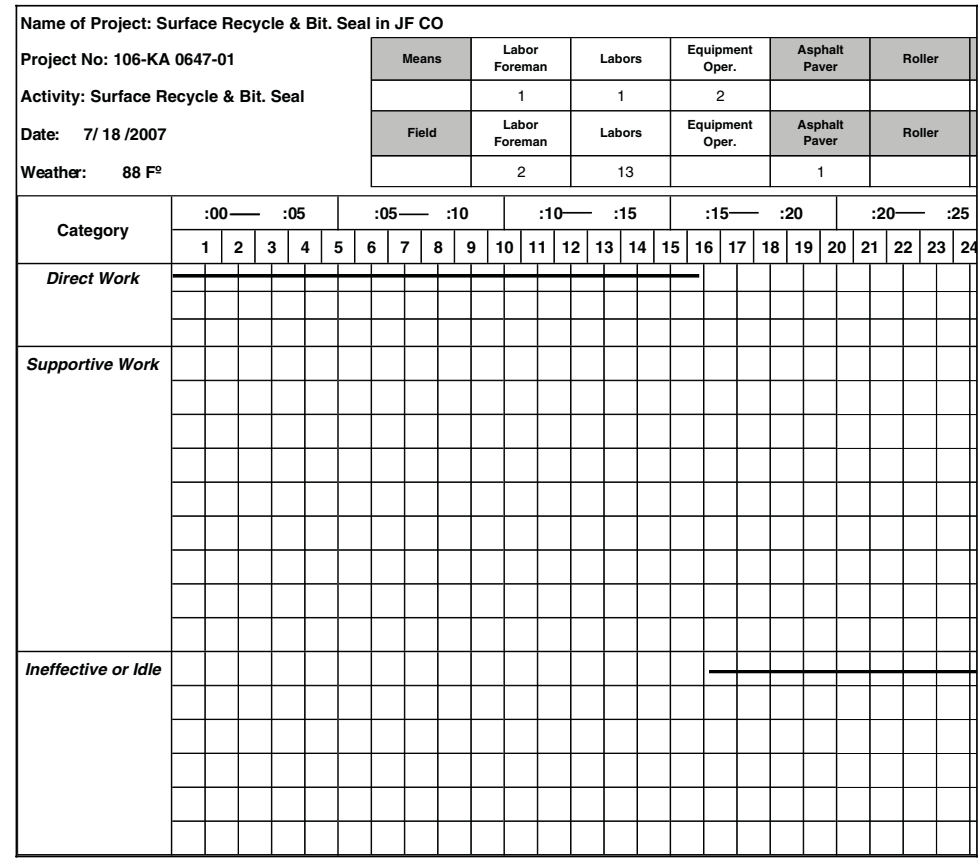

(a)

\begin{tabular}{|c|c|c|c|c|c|c|}
\hline \multirow{2}{*}{ No. } & \multicolumn{2}{|c|}{ Stopwatch } & \multicolumn{2}{c|}{ WRITE System } & \multicolumn{2}{c|}{ Difference } \\
\cline { 2 - 7 } & Work & Non & Work & Non & Work & Non \\
\hline 1 & 1,800 & 0 & 1,800 & 0 & 0 & 0 \\
\hline 2 & 3,600 & 0 & 3,550 & 50 & 50 & -50 \\
\hline 3 & 3,600 & 0 & 3,600 & 0 & 0 & 0 \\
\hline 4 & 420 & 180 & 300 & 300 & 120 & -120 \\
\hline 5 & 3,480 & 120 & 3,480 & 120 & 0 & 0 \\
\hline 6 & 3,060 & 240 & 3,060 & 240 & 0 & 0 \\
\hline 7 & 3,300 & 300 & 3,400 & 200 & -100 & 100 \\
\hline 8 & 960 & 540 & 960 & 540 & 0 & 0 \\
\hline 9 & 3,240 & 360 & 3,180 & 420 & 60 & -60 \\
\hline 10 & 2,760 & 840 & 2,820 & 780 & -60 & 60 \\
\hline 11 & 3,540 & 60 & 3,420 & 180 & 120 & -120 \\
\hline 12 & 3,600 & 0 & 3,600 & 0 & 0 & 0 \\
\hline 13 & 960 & 840 & 980 & 820 & -20 & 20 \\
\hline 14 & 2,100 & 600 & 1,970 & 730 & 130 & -130 \\
\hline 15 & 3,600 & 0 & 3,600 & 0 & 0 & 0 \\
\hline 16 & 3,600 & 0 & 3,600 & 0 & 0 & 0 \\
\hline 17 & 3,240 & 360 & 3,210 & 390 & 30 & -30 \\
\hline 18 & 3,180 & 420 & 3,050 & 550 & 130 & -130 \\
\hline 19 & 655 & 2,945 & 720 & 2,880 & -65 & 65 \\
\hline 20 & 3,000 & 600 & 3,000 & 600 & 0 & 0 \\
\hline 21 & 0 & 3,600 & 0 & 3,600 & 0 & 0 \\
\hline 22 & 0 & 3,600 & 0 & 3,600 & 0 & 0 \\
\hline Total & 53,695 & 15,605 & 53,300 & 16,000 & 395 & -395 \\
\hline
\end{tabular}

(b)

FIGURE 5 Data collection form and sample data.

a recycling agent. This asphalt recycling method allows crews to remove the deteriorated asphalt pavements by eliminating surface irregularities and cracks up to 2 in. in depth without any loss of the original pavement. The major HIR operations identified by the Asphalt Recycling and Reclaiming Association include heating, scarifying, rejuvenating, leveling, reprofiling, laying new hot mix, and compacting $(15,16)$.

Two HIR asphalt rehabilitation projects were carried out on K-192 near Winchester, Kansas, and K-16 near Tonganoxie, Kansas (Figure 7). The total length of highway was $23.8 \mathrm{mi}$. The contractor, Dustrol, Inc., was awarded these projects at the cost of $\$ 1,768,101$ and completed them in 12 working days, from July 5 to July 20,

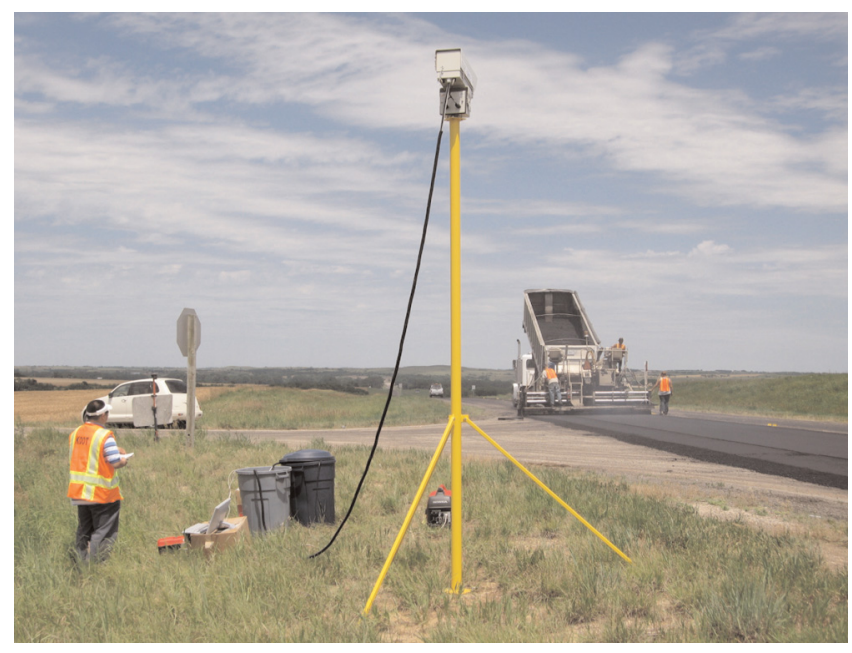

FIGURE 6 Field experiment on measuring productivity of HMA overlay.
2007. Productivity data were collected for 10 days, from July 9 to July 20, 2007.

\section{Steel Girder Bridge Construction}

From March 24 to 26, 2008, researchers measured the cycle times of a randomly selected laborer in a bridge beam setting operation called bolting (Figure 8). In addition, labor productivity data were collected by using the WRITE system for 2 months from March 24 to May 23, 2008. This data set was used to statistically compare labor productivity data collected from construction documents, such as the contractor's daily report and pay estimates.

A steel girder bridge reconstruction project over Interstate 70 in Lawrence, Kansas, was selected because steel girder bridges are the most common short span bridges in the United States. They feature long-lasting structures, easy construction, and economical cost (17). The Kansas Turnpike Authority awarded this 327.8-ft bridge reconstruction project to a contractor for the total price of $\$ 1.9$ million, and the period of construction was about 4 months, from February to June in 2008.

\section{DATA ANALYSIS}

The two-step approach was used for the data analyses using the SAS. First, data normality tests were performed to determine whether data had a normal distribution because data normality was a required assumption for the hypothesis test using the paired $t$-test. Second, if data had a normal distribution after normality tests, a paired $t$-test would be conducted as a parametric test to compare two productivity measurement methods. If data did not have a normal distribution, the Wilcoxon signed-rank test would be carried out. Columns 1 to 4 of Table 1 show the description of measurement 


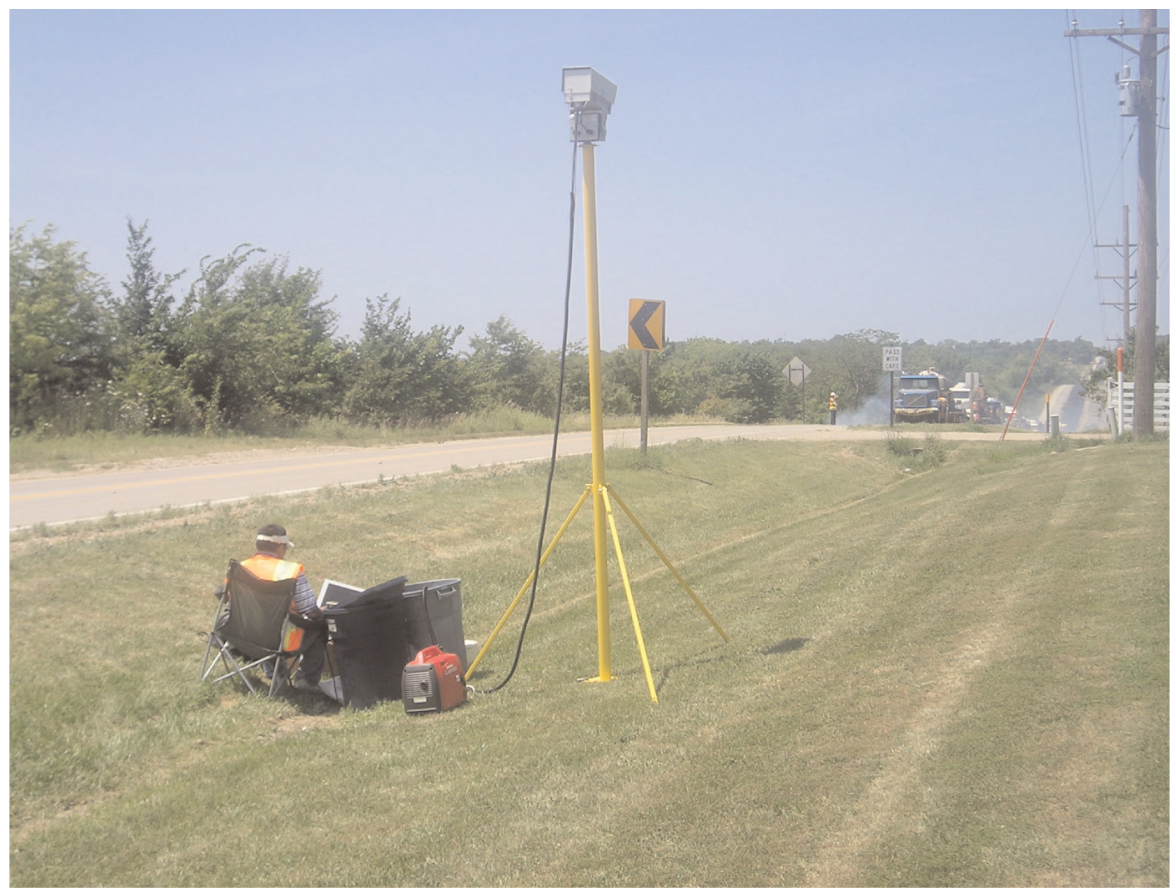

FIGURE 7 Field experiment on measuring productivity of HIR.

data, and the rest of Table 1 shows $p$-values of normality tests and comparison tests.

\section{Normality Tests}

Two normality tests, the Shapiro-Wilk test and the Anderson-Darling test, were conducted to determine whether the experimental data followed normal distribution, as shown in Table 1. As shown in Columns 5 and 6 of Table 1, the $p$-values of HMA overlay, .6966 and .2500 , were higher than the significance level of 5\%, indicating that the differences in cycle time for the HMA overlay operation measured by the stopwatch and the WRITE system were normally distributed. Thus, the paired $t$-test was used for this data set. For

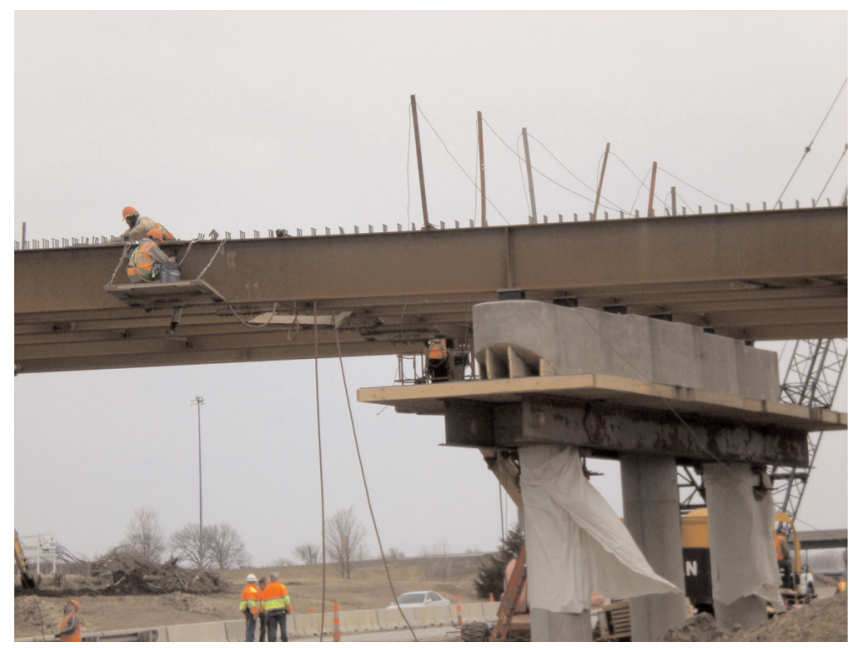

FIGURE 8 Bolting bridge beam operation. computed $p$-values lower than the significance level of 5\%, the null hypothesis that measurements follow normal distribution was rejected at the significance level of 5\%. This means that at this significance level, working time and nonworking time measured by the stopwatch and the WRITE system in the HIR and bolting operations were not normally distributed. Therefore, it was concluded that a nonparametric test, the Wilcoxon signed-rank test, was needed to analyze the data.

\section{Hypothesis}

Productivity data from the highway operations obtained by using the WRITE system were compared with the stopwatch method to determine whether the mean values of these two groups of data were the same. The null hypothesis and alternative hypothesis for these analyses are as follows:

$H_{0}$ :

$\mu_{d}=0$

$H_{1}$ :

$\mu_{d} \neq 0$

where $\mu_{d}$ is the mean difference of data measured by the stopwatch and by the WRITE system methods.

\section{Paired $t$-Test}

The paired $t$-test, a parametric test, was conducted to identify whether there were significant differences between the HMA overlay productivity data measured by the stopwatch and by the WRITE 


\begin{tabular}{|c|c|c|c|c|c|c|c|}
\hline \multirow[b]{2}{*}{ Operation } & \multirow[b]{2}{*}{ Operation Type } & \multirow[b]{2}{*}{ Measurement Unit } & \multirow[b]{2}{*}{ No. of Cycles } & \multicolumn{2}{|c|}{ Normality Test ( $p$-value) } & \multicolumn{2}{|c|}{$\begin{array}{l}\text { Comparison Test } \\
\text { ( } p \text {-value) }\end{array}$} \\
\hline & & & & Shapiro-Wilk & $\begin{array}{l}\text { Anderson- } \\
\text { Darling }\end{array}$ & $\begin{array}{l}\text { Paired } \\
t \text {-Test }\end{array}$ & $\begin{array}{l}\text { Wilcoxon } \\
\text { Signed Rank }\end{array}$ \\
\hline HMA overlay & Equipment intensive & Seconds per cycle & 9 & .6966 & .2500 & .9830 & \\
\hline HIR & Equipment intensive & Seconds per hour & 60 & .0001 & .0050 & & .2500 \\
\hline Bolting (bridge project) & Labor intensive & Seconds per $5 \mathrm{~min}$ & 231 & $<.0001$ & $<.0001$ & & .5710 \\
\hline
\end{tabular}

system methods. With the use of the two-tailed $t$-test, the null hypotheses cannot be rejected at the $5 \%$ significance level, as the $p$-value is .9830 (Table 1). These results indicated that, statistically, there were no differences between productivity measurements taken by the WRITE system and by the stopwatch method.

\section{Wilcoxon Signed-Rank Test}

A nonparametric test, the Wilcoxon signed-rank test, was used for the HIR and bolting bridge beam operations. As shown in Table 1, test results indicated that the null hypothesis was accepted at the 5\% significance level because two computed $p$-values, .25 and .571 , were greater than the value of .05 . Thus, statistically, there were no differences in the mean values of the two productivity measurements collected by using the conventional methods and the WRITE system. Analysis results indicated that, statistically, the working times for HIR and bolting bridge beams as measured by the stopwatch and the WRITE system were the same.

\section{Comparison of Productivity Data from the WRITE System and Construction Documents}

In addition to comparing work sampling data between the WRITE system and the stopwatch method, productivity data collected from the WRITE system were compared with productivity data by using construction documents, such as pay estimate documents and contractor's daily reports. A total of 6,455 labor hours were measured out of the total of 10,312 project hours. A total of 14 activity-level and 129 operation-level productivity data were collected from the bridge reconstruction project. After normality tests, the paired $t$-test was conducted to determine whether there were significant differences between productivity data measured by conventional methods and the WRITE system method. With the two-tailed $t$-test, the null hypotheses cannot be rejected at the 5\% significance level, as shown in Table 2 . These results indicated that, statistically, there were no differences between productivity measurements taken by the WRITE system and the productivity data collected by using conventional methods, such as pay estimate documents and contractor's daily reports.

\section{CONCLUSIONS AND RECOMMENDATIONS}

An advanced on-site construction productivity measurement method was developed by using wireless technologies. The system can measure construction equipment and labor productivity with minimum expense and without interfering with construction crews.
The WRITE system was compared with the conventional productivity measurement methods of the stopwatch and construction documents. Statistical analysis results proved that the WRITE system produced productivity measurements identical to the conventional methods in highway construction operations. Thus, the WRITE system can be used as an alternative to the construction productivity measurement methods.

The WRITE system satisfies the following basic criteria for being an ideal method for measuring construction productivity. The WRITE system is simple, inexpensive, consistent and replicable, reflective of what actually occurs at the site, and expeditious. The WRITE system costs less than $\$ 7,500$ to put together, making it an inexpensive system compared with the variety of construction equipment used in project sites. The software is easy to use. Anyone who knows how to use Microsoft Office should have no problem using the WRITE system software. The hardware is also easily installed, as shown in Figures 1 and 3. Using real-time productivity data, engineers and project managers may be able to accurately determine the progress of highway construction and easily share the information with all parties involved in the projects. Thus, the wireless real-time productivity measurement technology promises to address cost overruns, improve construction schedule forecasts, and increase emergency response capability after extreme events. In addition, the technology is able to provide data for engineers and project managers to analyze on-site construction productivity in real time. Thus, actions can promptly be taken to address on-site productivity problems and improve construction operations. The WRITE system provides a platform to share the real-time productivity data among owners, engineers, contractors, and material suppliers, as a result, improving communication and coordination among construction project participants.

However, the WRITE system in the current format has some limitations. It is difficult or impossible to cover the entire con-

TABLE 2 Results of Data Analyses on Activity and Operation Level Comparison

\begin{tabular}{|c|c|c|c|c|}
\hline & & & $\begin{array}{l}\text { Normality } \\
\text { Test } \\
\text { ( } p \text {-value) }\end{array}$ & $\begin{array}{l}\text { Comparison } \\
\text { Test } \\
\text { ( } p \text {-value) }\end{array}$ \\
\hline Variable & $\begin{array}{l}\text { Measurement } \\
\text { Unit }\end{array}$ & $\begin{array}{l}\text { Degrees of } \\
\text { Freedom }\end{array}$ & $\begin{array}{l}\text { Shapiro- } \\
\text { Wilk }\end{array}$ & $\begin{array}{l}\text { Paired } \\
t \text {-Test }\end{array}$ \\
\hline Activity & $\begin{array}{l}\text { Labor hours } \\
\text { per unit }\end{array}$ & 13 & .1284 & 86.5 \\
\hline Operation & $\begin{array}{l}\text { Labor hours } \\
\text { per unit }\end{array}$ & 128 & .0510 & 1.627 \\
\hline
\end{tabular}


struction site by using only one camera house, particularly if the site is very large. The images may not be clear enough for human eyes to distinguish types of construction operations. Even if the images are clear, there is still the possibility that a person might misinterpret the construction operations. Thus, continuous human involvement is required to analyze the data. Such methods are prone to errors because of human biases and limitations in addition to the time delay.

To address these shortcomings, the WRITE system and the human pose analyzing algorithm using the artificial neural network were developed to automatically determine on-site labor productivity. The results indicated that the developed algorithm had the highest accuracy in predicting effective work and the lowest in contributory work (18). In addition, a computer vision-based video interpretation model was developed to automatically extract productivity information from videos of construction operations in real time (19). If these image process technologies are used regularly with the WRITE system, project management would be able to collect and analyze construction productivity data with greatly reduced effort and cost. Although current technology has improved productivity measurement speed, data collection effort, and data cost, development of modeling processes may not be as fast as required by the construction industry.

This research project made several major contributions to the advancement of knowledge in the construction industry. First, it advances the application of wireless technologies in highway construction operations. Second, the developed WRITE system is capable of continuously collecting on-site construction productivity data so that engineers and project managers can determine productivity in real time. Third, productivity data gathered by the WRITE system can be sent to a website so that owners, engineers, contractors, and material suppliers are able to share data and take necessary actions in real time, as long as they have Internet access. With these advancements, communication and coordination will be improved at the construction site. Consequently, the WRITE system will enhance the owners' and contractors' ability to manage construction projects.

Besides the additional validation on the WRITE system, this research project can be extended in several ways. First, because the process of determining working status with the live images obtained from the WRITE system is time-consuming and subject to human error and biases, there is a need to develop an algorithm to automatically classify working or nonworking actions on the basis of human poses associated with construction activities. Second, it is necessary to install at least two cameras to cover the entire project site of either the bridge or the paving projects. Thus, with additional cameras, there is a need to develop a user interface and algorithms that can be used to collect, store, retrieve, manipulate, transform, and display the data sent by the different cameras. Third, by using the WRITE system, it may be possible to identify resources in construction job sites and integrate the information with the project management database system. Fourth, the WRITE system can be integrated with automatic image analysis methods, which may enable the industry's development of benchmark data for continuous highway productivity improvement. Finally, the developed WRITE system may be able to measure the quantity of lost productivity during the construction operations, which is beyond current capability in the construction industry.

\section{ACKNOWLEDGMENTS}

This research was funded in part by the Transportation Research Institute at the University of Kansas, provided by the Research and Innovative Technology Administration, U.S. Department of Transportation, as well as by the National Science Foundation.

\section{REFERENCES}

1. Mason, R. L., R. F. Gunst, and J. L. Hess. Statistical Design and Analysis of Experiments, 2nd ed. Wiley, Hoboken, N.J., 2003.

2. Frigon, N. L., and D. Mathews. Practical Guide to Experimental Design. Wiley, New York, 1997.

3. Ghanem, A. G., and Y. A. Abdelrazig. A Framework for Real-Time Construction Project Progress Tracking. Presented at 10th Biennial International Conference on Engineering, Construction, and Operations in Challenging Environments, League City/Houston, Tex., 2006.

4. Pan, N.-F. Assessment of Productivity and Duration of Highway Construction Activities Subject to Impact of Rain. Expert Systems with Applications, Vol. 28, No. 2, 2005, pp. 313-326.

5. Noor, I. Measuring Construction Labor Productivity by Daily Visits. Presented at AACE International. Transactions of the Annual Meeting, Cincinnati, Ohio, 1998

6. Burton, F. M. Methodology for Measuring Construction Productivity. Presented at Transactions of the American Association of Cost Engineers, Seattle, Wash., 1991

7. Teicholz, P. U.S. Construction Labor Productivity Trends, 1970-1998. ASCE Journal of Construction Engineering and Management, Vol. 127, No. 5, 2001, pp. 427.

8. Oglesby, C. H., H. W. Parker, and G. A. Howell. Productivity Improvement in Construction. McGraw-Hill, Inc., New York, 1989.

9. Su, Y. Y., and L. Y. Liu. Real-Time Construction Operation Tracking from Resource Positions. Presented at 2007 ASCE International Workshop on Computing in Civil Engineering, Pittsburgh, Pa., 2007.

10. Navon, R., and Y. Shpatnitsky. Field Experiments in Automated Monitoring of Road Construction. ASCE Journal of Construction Engineering and Management, Vol. 131. No. 4, 2005, pp. 487-493.

11. Bosche, F., C. T. Haas, and B. Akinci. Automated Recognition of 3D CAD Objects in Site Laser Scans for Project 3D Status Visualization and Performance Control. ASCE Journal of Computing in Civil Engineering, Vol. 23, No. 6, 2009, pp. 311-318.

12. Thomas, H. R., and D. F. Kramer. Definition of Productivity. The Manual of Construction Productivity Measurement and Performance Evaluation. Publication SD-35. Construction Industry Institute, Austin, Tex., 1988.

13. Meyers, F. E. Motion and Time Study. Prentice-Hall, Englewood Cliffs, N.J., 1992.

14. Thomas, H. R. Labor Productivity and Work Sampling: The Bottom Line. ASCE Journal of Construction Engineering and Management, Vol. 117, No. 3, 1991, pp. 423-444.

15. Button, J. W., C. K. Estakhri, and D. N. Little. Overview of Hot In-Place Recycling of Bituminous Pavements. In Transportation Research Record: Journal of the Transportation Research Board, No. 1684, TRB, National Research Council, Washington, D.C., 1999, pp. 178-185.

16. Kandhal, P. S., and R. B. Mallick. Pavement Recycling Guidelines for State and Local Governments-Participants Reference Book. Publication FHWA-SA-98-042. FHWA, U.S. Department of Transportation, 1997.

17. Barker, R. M., and J. A. Puckett. Design of Highway Bridges. Wiley, New York, 1997.

18. Bai, Y., L. Huan, A. Peddi, and S. Kim. Determination of On-Site Construction Labor Productivity Using Artificial Neural Networks. Presented at 89th Annual Meeting of the Transportation Research Board, Washington, D.C., 2010.

19. Gong, J., and C. H. Caldas. Computer Vision-Based Video Interpretation Model for Automated Productivity Analysis of Construction Operations. ASCE Journal of Computing in Civil Engineering, Vol. 24, No. 3 , 2010, pp. 252-263.

The Construction Management Committee peer-reviewed this paper. 